\title{
(Re) Making gender in the clinical context: a look at how ideologies shape the medical construction of gender dysphoria in Portugal
}

\section{Ana Patrícia Hilário ${ }^{1}$}

Published online: 16 April 2019

(c) The Author(s) 2019

\begin{abstract}
The act of diagnosing gender dysphoria (GD), as in the act of diagnosing any other condition, is structured by socio-cultural, political and economic factors and is conducted by social actors. Drawing upon in-depth interviews with practitioners who work with trans people in Portugal, the study reveals the nuances and complexities surrounding the diagnostic attribution of GD and the ways in which the ideologies regarding gender shape this attribution. Practitioners' accounts show a diversity not often acknowledged within sociological and transgender literature. We extend previous studies by demonstrating that practitioners who operate under a social model of gender are opening space for trans people to be treated as experts of their bodies and identities by accepting the existence of those who identify beyond gender binaries. While it might not be true for practitioners who can be positioned within a biological model, thus attributing an essentialist explanation of gender, we found evidence that practitioners who follow a social model are allowing room for the self-definition of gender identification. The study provides another lens for understanding the diagnostic attribution of GD by paying attention to the accounts of practitioners who work with trans people and reveals their openness towards a collaborative model of care.
\end{abstract}

Keywords Trans people $\cdot$ Gender dysphoria $\cdot$ Diagnosis $\cdot$ Gender $\cdot$ Ideologies

\section{Introduction}

Trans people in Portugal (Pinto and Moleiro 2012) and in other countries with a welfare state (Linander et al. 2017a) need to obtain a diagnosis of Gender Dysphoria (GD) to access gender-confirming medical procedures (i.e. hormone

Ana Patrícia Hilário

patriciahilario@gmail.com

1 Instituto de Ciências Sociais, Universidade de Lisboa, Av. Professor Aníbal de Bettencourt, 9, 1600-189 Lisboa, Portugal 
therapy and/or gender-confirming surgery). The field of GD has been marked by conflicting arguments regarding its definition and its establishment as a psychiatric diagnosis category as it enhanced the pathologization of trans identities (Dewey and Gesbeck 2017). While we do not intend to provide here a detailed analysis of the struggles surrounding depathologization, it is important to outline that this involves objections to how medical institutions have constructed GD and the power that have been given to medical professionals on behalf of society in general for controlling access to gender-confirming medical procedures and therefore maintaining a gender binary order (Davis et al. 2016). When employing a gatekeeping role, practitioners limit the access to GD diagnosis to trans people if they do not meet the expectations of what they consider to be the appropriate gender (Johnson 2015).

Following this train of thought, trans medical encounters appear to be marked by the search for the true or authentic trans identity (McQueen 2016) which draws upon the imaginary of binary genders. Within this imaginary, gender identity is derived from genitalia and it is deeply interwoven with heterosexuality, which structures gender (Schilt and Westbrook 2009). Those who do not present a fixed and stable gender identity across the life course (McQueen 2016) and who do not wish to undergo gender-confirming surgery to align their assigned gender at birth with their gender identity (Johnson 2015) might not be considered to be trans enough (Mog and Swarr 2008) to obtain GD as they challenge the gender binary order (Davis et al. 2016). What this appears to suggest is that transspecific healthcare tends to draw upon an essentialist/biologist ideology which pathologises gender variance (Davis et al. 2016). Indeed, by employing a gatekeeping role, practitioners are not recognizing gender diversity and might to a certain extent be harming trans people who do not define themselves within a gender binary framework (Hilário 2018).

GD is a prime example of how the attribution of a disorder for which there are no confirmatory biomarkers or scientific tests can be particularly challenging for medicine (Shuster 2016) and might not always work in the best interests of trans people (Davis et al. 2016) as they might feel pressured to fit into a clinical category (Turowetz and Maynard 2016). Without biological evidence to support decisions on GD, and as the diagnostic attribution is based upon the "distress that may accompany the incongruence between one's experienced or expressed gender and one's assigned gender" (APA 2013, p. 451), practitioners tend to deal with the uncertainty that characterizes the diagnosis of GD by employing gatekeeping practices that are understood by them as a tool to prevent regret regarding permanent bodily interventions such as genital surgery and infertility due to hormone therapy (Shuster 2016). Thus, there is a danger that practitioners base their decisions on the attribution of GD on their own assumptions regarding the nature of gender (Whitehead et al. 2012) which might not allow room for the gender self-definition of trans people (Linander et al. 2017b). Research into the diagnosis of GD and its attribution that has privileged the standpoint of practitioners concerning this matter is scarce, particularly in non-English speaking countries (Richard et al. 2014). This paper intends to overcome this gap and shed light on how the ideologies employed by practitioners regarding gender shape the diagnostic attribution of GD to trans people in Portugal. 


\section{An overview of the diagnosis of gender dysphoria}

Transsexualism was the first diagnostic category used under the umbrella of psychosexual disorders in 1980; fourteen years later it was reclassified under sexual disorders and, more recently, it was removed from the section on sexual dysfunction and paraphilic disorders in the Diagnostic and Statistical Manual of Mental Disorders of the American Psychiatric Association-APA (Hilário 2018). The name change from Gender Identity Disorder (1994) to Gender Dysphoria (2013) in DSM was intended to destigmatize and depathologize trans people by paying attention to the distress experienced due to gender non-conformity rather than diagnosing everyone who experienced gender incongruence (Dewey and Gesbeck 2017). These changes followed the recommendation of the World Health Organization (WHO) in the International Statistical Classification of Diseases and Related Health Problems (ICD). While this paper was being written, the WHO released an updated version of ICD11 on 18 June 2018 , within which this diagnostic category is to be placed under the umbrella of conditions relating to sexual health. It is expected that changes in DSM will take place. Until then, practitioners who work with trans people in Portugal and elsewhere still follow the clinical guidance of the American Psychiatric Association in DSM-5 (APA 2013) and the recommendations in the 7th version of the Standards of Care (SOC) for the Health of Transsexual, Transgender, and Gender Nonconforming People (WPATH 2011). While in SOC-7 a recommendation letter to access gender-confirming medical procedures is no longer necessary, trans people must still demonstrate that they experience persistent GD and a psychosocial assessment by a qualified practitioner to ensure they have the capacity to make informed decisions is mandatory (Dewey and Gesbeck 2017). The SOC-7 outlines a collaborative approach to care, based on an informed consent model, as a means to provide answers to problems concerning access, provision and delivery of trans-specific healthcare across the globe (Davy 2015).

\section{The Portuguese context}

Research conducted so far in Portugal, which has examined practitioners' and trans people's experiences of healthcare, has not sufficiently addressed the process of the diagnostic attribution of GD (Pinto and Moleiro 2012). The country offers an interesting context in which to explore the lives of trans people, as it has been at the forefront of LGBT rights. It was the first European country to prohibit discrimination based on sexual orientation in its Constitution and the eighth country worldwide to legally accept same sex marriage (Santos 2013). The 2011 Gender Identity Law, which aimed to facilitate the legalization of gender and name changes, is also representative of LGBT rights in Portugal. Since the approval of this law, trans people can change their birth certificate by presenting the diagnosis of GD to the Portuguese Civil Registry. A diagnosis of GD must be obtained from two independent, medical and/or psychological practitioners who are part of a list approved by the 
Medical Council ${ }^{1}$ and it is the first step in the medical transitioning process, prior to gender-confirming medical procedures. All trans people who have a diagnosis of GD can access, through the welfare state, psychological/psychiatric support by a mental health practitioner as well as hormone therapy by an endocrinologist in five public hospitals across the country and gender-confirming surgery in a hospital located in the centre of Portugal (Hilário 2018). A law which establishes the right to a legal gender recognition procedure based on self-determination has been recently approved by the Portuguese parliament with the support of the government and left wing parties (Decree Law No. 203/XIII) ${ }^{2}$. This law enables the separation of medical and legal gender recognition. The terms self-determination and self-definition of gender identification will be used interchangeably here as one signifies the other (Hilário 2018).

\section{Terminology}

For the current study, we will use the abbreviated term trans to refer to people who, in general terms, do not feel aligned with the gender assigned to them at birth and to avoid an unnecessary distinction between transsexual and transgender people (Pfeffer 2010; Hilário 2018). While the term transsexual has commonly been used within the medical domain to describe, in the main, individuals who have done (or wish to do) gender-confirming medical procedures to align their physical body with their gender identity, the term transgender refers not only to transsexual people, but also to individuals who do not wish to undergo gender-confirming medical procedures, albeit they do not feel aligned with their gender assigned at birth, and refers to different gender identities and expressions (Sanger 2010; Hilário 2018). Trans people might wish to pursue hormone therapy (for breast augmentation, body hair development, menstrual cessation and/or clitoris enlargement), top surgery (for breast augmentation or removal), chest and/or facial reconstruction and genital surgery (namely metoidioplasty or phalloplasty and vaginoplasty). Voice therapy or body hair removal might be important for trans people as well as other non-medical procedures such as packing, tucking and binding. In Portugal, and in other non-Anglophone countries (Platero 2011), the term transsexual has been used independently of the gender-confirming medical procedures that the person has done or wishes to do (Pinto and Moleiro 2015). Trans people might define themselves within a binary (either man or woman) or non-binary model of gender (neither man nor woman). The latter is the case of genderqueer individuals. While transgender is an identity, GD is a diagnostic category that refers to individuals who experience distress due to the incongruence they feel between their experienced or expressed gender and their assigned gender at birth (APA 2013; Shuster 2016; Hilário 2018).

\footnotetext{
${ }_{1}$ Available at: http://www.irn.mj.pt/IRN/sections/irn/a_registral/registo-civil/docs-do-civil/lista-de-clini cos/downloadFile/file/Lista_profissionais_habilitados_assinar_relatorios.pdf?nocache=1436274751.05.

${ }^{2}$ Available at: http://app.parlamento.pt/webutils/docs/doc.pdf?path=6148523063446f764c3246795 95842774f6a63334e7a637664326c755a47566a636d563062334d7657456c4a5353396b5a574d794d444d $7457456 \mathrm{c} 4 \mathrm{a} 5353356 \mathrm{~b} 62324 \mathrm{~d} 3 \mathrm{~d} \&$ fich $=$ dec203-XIII.doc\&Inline $=$ true .
} 


\section{Background}

Research suggests that practitioners tend to limit the attribution of GD diagnosis and access to trans-specific healthcare to trans identities which do not correspond to their gender expectations (Davis et al. 2016). Within sociological and transgender literature, it has been said that practitioners' expectations about trans people tend to draw upon the heterosexual imaginary, i.e. "that way of thinking which conceals the operation of heterosexuality in structuring gender and closes off any critical analysis of heterosexuality as an organizing institution" (Ingraham 1994, pp. 203-204). Thus, trans people who correspond to these heteronormative ideals are those who intend to align their assigned gender at birth with their gender identity through gender-confirming medical procedures, particularly genital surgery (Davis et al. 2016) and to engage in heteronormative relationships (Schilt and Westbrook 2009).

As heterosexuality is "predicated on the seemingly natural attraction between two types of bodies defined as opposites", it is understandable that what is at the heart of heteronormativity is the "taken-for-granted expectation that heterosexuality and gender identity follow from genitalia" (Schilt and Westbrook 2009, p. 443). Trans people who do not correspond to the heteronormative ideal of female-bodied women and male-bodied men challenge heteronormativity, therefore presenting a contradictory embodiment (Connell 2012), so they are placed in a less privileged position than those who correspond to the imaginary of gender binary (Johnson 2015). Within this light, trans people might feel the need to do transgender (Connell 2010) to obtain the diagnosis of GD and thereby access trans-specific healthcare and/or legal gender recognition (Dewey and Gesbeck 2017; Hilário 2017). Within the diagnostic attribution of GD, practitioners tend to place an unnecessary burden on trans people to define themselves in accord with the gender binary imaginary and to be certain about undergoing gender-confirming medical procedures to align their assigned gender at birth with their gender identity, i.e. to correspond to the authentic trans ideal (Johnson 2015; Davis et al. 2016).

When practitioners decide who is an authentic trans person and can therefore access the diagnosis of GD, they appear to operate under an essentialist/biological model within which gender identity is understood as a product of biological processes (Johnson 2015). The biological model locates gender identity within the individual's brain and draws upon the assumption that cross-gender identification is persistent from birth. This position contrasts with that expressed by practitioners who tend to operate under a social model, which understands gender identity as being something flexible and mutable (Whitehead et al. 2012). Thus, practitioners who operate under a social model might open space for non-binary gender identities by allowing room for trans people to define themselves in their own terms. While there is some work on the diagnostic attribution of GD (Johnson 2015; Davis et al. 2016; McQueen 2016; Dewey and Gesbeck 2017), little has been said about how, within this diagnostic attribution, practitioners might challenge dominant ideologies concerning gender by opening space to the existence 
of other forms of gender identity and expression outside the binary gender (Whitehead et al. 2012), especially in the Portuguese context. Portugal is characterized by a strong welfare state and as such states tend to be characterized by a paternalistic approach (Linander et al. 2017b); it is not surprising that practitioners employ gatekeeping practices that limit access to trans-specific healthcare of trans people who do not conform to the gender binary ideal (Pinto and Moleiro 2012). This might, nevertheless, not be so straightforward in the light of the political debate surrounding the self-determination of trans people that has recently taken place there (Hilário 2018).

\section{Methods}

\section{Overview of the study}

This article draws evidence from a wider study about trans lives and the institutional apparatus that frames them. The TRANSRIGHTS: Gender citizenship and sexual rights in Europe: Transgender lives in transnational perspective study intends to explore how legal and institutional frameworks impact on the lives of trans people in five European countries-Portugal, the United Kingdom, France, Sweden and the Netherlands. These countries were chosen due to their different institutional frameworks concerning gender and sexuality, welfare policies and practices, and sexual and transgender rights (Castagnoli 2010). However, for this article we focus on practitioners who work with trans people in Portugal as it was the only country while this article was being written where fieldwork has been completed. To address the overall aim of the study, a qualitative research approach was adopted and in-depth interviews with practitioners were carried out by the TRANSRIGHTS team (identified here as T) during 2016. The interviews followed an interview schedule open enough to capture individual singularities and included questions such as: Which steps and requisites are necessary to establish a diagnosis? What is your role in that process? What type of diagnosis is needed today? When do you know a person should really change their gender? Do most trans people want gender-confirming surgery or not? What do you normally say to people who do not want to change their genitalia, or do not have a defined gender? We will pay specific attention here to the diagnostic attribution of Gender Dysphoria.

\section{Participants}

Participants were recruited via a list of practitioners, approved by the Medical Council, ${ }^{3}$ who were able to confirm and sign the diagnosis of Gender Dysphoria which would enable trans people to access gender-confirming medical procedures, as well as legally change their gender and name. Whereas the law on gender self-determination ${ }^{4}$ was

\footnotetext{
${ }^{3}$ See footnote 1 .

${ }^{4}$ See footnote 2 . 
approved while this article was being written, the 2011 Gender Identity Law was still in place when the interviews for this study were being conducted by the TRANSRIGHTS team. An email explaining the study and asking for collaboration was sent to the practitioners mentioned in the list. Participants were also recruited through snowball sampling, as social networks were used to contact some practitioners. Ten practitioners, namely four psychologists, four psychiatrists and two endocrinologists, with a specialization in sexology, agreed to be interviewed. The practitioners were aged between 30 and 70 and had between 10 and 40 years' experience of working with trans people; two worked exclusively in the public system; four in the private system; four both in the public and private sector, and all practitioners, except for one medical practitioner, specialized in trans issues. The small number of participants reflects the limited number of practitioners who can work with trans people and sign the diagnosis of GD according to the list.

\section{Procedure}

Ethical approval was granted by the Instituto de Ciências Sociais, Universidade de Lisboa and the European Research Council Executive Agency. Clearance was also given by the Portuguese National Commission for Data Protection. Information about the aims and procedures of the study and that their participation was voluntary was provided to participants. They were also aware of their right to skip any question and to withdraw from the study at any stage. The terms of confidentiality and use of the information gathered in the interview were outlined. It was made clear that results would be reported in such a way that no individual would be identifiable. The interviews were conducted in practitioners' offices after they signed the informed consent form, and lasted between 1 and $3 \mathrm{~h}$. All the interviews were tape recorded with participants' permission and, after verbatim transcription in Portuguese by a member of the TRANSRIGHTS team, were transferred to the MAXqda2007 program for storage and coding. Selected quotations were translated into English.

\section{Data analysis}

The study drew upon a social constructivist approach and a thematic analysis was developed (Braun and Clarke 2006). To begin, after the careful reading of all transcripts, first-order themes were identified through an open coding procedure and this helped to produce a preliminary list of themes. These themes were reduced through focused coding to core themes. Then, through selective coding, we identified three main themes concerning the diagnostic attribution of GD, which will be outlined in Findings section.

\section{Findings}

This section will examine how the diagnostic attribution of GD is constructed by practitioners in Portugal and the ways in which biological and social ideologies concerning gender might shape this construction. Drawing upon our data analysis, we 
will focus on three core themes: (a) the alignment of the body and gender identity; (b) the importance of cross-gender transitioning; and (c) struggling and accepting gender non-conformity.

\section{The alignment of the body and gender identity}

We aimed first and foremost to understand GD diagnosis and what was at stake for its attribution on the part of practitioners. When asked to explain GD, the practitioners interviewed offered an explanation on gender identity as they believed that this concept was important in understanding the diagnosis of GD. What became apparent was that most practitioners appeared to interpret GD within what has been referred to as a biological model of gender (Whitehead et al. 2012). This was the case of Claudia who made the following statement:

The main criteria, is the person feeling discomfort.... which is a much-attenuated form... Well, basically it is a huge suffering of not identifying with the body that one has. At the end... at the end we confirm... we confirm repeatedly that there is a huge incongruence between gender identity, which is a mental identity, thus cerebral, and the body that one has. That is, I feel I am a man but I am in a woman's body. Well, the basic criteria for the diagnosis is that.

(Practitioner, 60 years old, 40 years of practice, 30 years working with trans people)

The above quote suggests that the diagnostic criteria for GD privileges a gender binary definition and to a certain extent shows the determinism within which the biological model of gender identity is based. This was also evident in the discourse of other practitioners. For José gender identity is rooted in the brain and therefore has a biological cause:

They suffer because their brain is normal but is the opposite sex to their body. Well, the body is normal but is the opposite sex to their brain. This is why it is an illness.

(Practitioner, 70 years old, 40 years of practice, 12 years working with trans people)

According to the biological model, cross-gender identification is something persistent and stable throughout the person's life. Thus, this model does not appear to allow room for the existence of other narratives aside from that present from birth (McQueen 2016). While some practitioners appeared to adhere to the biological model of gender, others understood gender as something constructed throughout the person's life and thereby recognized the fluidity of gender identity, interpreting it within what has been called a social model (Whitehead et al. 2012). These findings contrast to Pinto and Moleiro's (2012) research on trans-specific healthcare practices in Portugal, where that kind of diversity was not found amongst practitioners. The statement made by Mário, who acknowledged the possibility of the creation of fluid 
gender identities, helps to demonstrate the variety of positions on the nature of gender identity:

Gender Dysphoria places the emphasis not on gender identity but on the suffering that one's gender identity might bring to the person. Suffering of oneself. In my understanding, it gives the sense that gender is more fluid. Even by being fluid... only the persons who suffer because of this would look for help. (Practitioner, 40 years old, 15 years of practice, 15 years working with trans people)

These findings confirm Whitehead et al. (2012) research on the clinical practice with trans people, where it was found that practitioners interpret the diagnosis of GD differently according to an identity-based gender ideology. This practitioner, like others who follow a social model, adopts a position which understands gender identity as fluid and therefore allows room for the diagnostic attribution of GD to people who do not correspond to the authentic trans identity (McQueen 2016). Without biomarkers or scientific tests to prove the diagnosis of GD (Shuster 2016), making decisions on the diagnostic attribution based on the identification of the authentic trans identity (McQueen 2016) is problematic as it relies on the assumption of the existence of a real man and woman (Hird 2002) and, therefore, constrains the validation of other forms of identity, apart from the normative gender binary, by practitioners. What this also means is that without the diagnosis of GD some trans people might not access gender-confirming medical procedures; even when trans people do not intend to do genital surgery, they might wish to undergo other gender-confirming medical procedures such as breast surgery or hormone therapy.

\section{The importance of cross-gender transitioning}

Practitioners seemed to base their medical decision about GD diagnosis on the information provided by trans people, particularly the feeling of discomfort regarding the incongruence between their assigned gender at birth and gender identity. We intended to understand the extent to which the feeling of discomfort was verified through one's wish to undergo gender-confirming surgery thus aligning genitalia and gender identity. What became evident in our findings was that cross-gender transitioning throughout gender-confirming surgery, particularly genital surgery, was key for most practitioners. The following comment made by André shows that the desire for gender-confirming surgery tended to be understood by practitioners as a strong gender marker:

A: What defines a transsexual person is that (i.e. genital surgery)! Do you understand? A person who arrives here and says: 'look I like a lot of my body but I do not want to do anything to my penis. I do not want to lose it. I just want to have a more feminine presentation and to take some hormones.' Do you think this is a transsexual?

T: Well... 
A: It isn't! There are those who say... even some colleagues of yours...that come here to say something... to say that they are. But they aren't! They aren't! They are not transsexuals! They are transvestites! Do you understand? (Practitioner, 45 years old, 20 years of practice, 20 years working with trans people)

André established a distinction between transsexuals and transvestites. The former category refers to those who wish to have genital surgery and thereby suffer from GD, whereas the latter, because they do not have this desire, are not allowed by practitioners to obtain a GD diagnosis and to undergo other gender-confirming medical procedures such as hormone therapy. In this light, trans people's desire to change their genitals and to correspond to the gender binary ideal of the real man and woman (Hird 2002) marks the determination of gender (Westbrook and Schilt 2014) and the category attribution (Turowetz and Maynard 2016) of GD diagnosis. The following statement made by Diogo helps to demonstrate this point:

T: There are people who for instance have a penis and at the same time have a feminine presentation and a beard. They claim to be non-binary. They say they are... The speech of these people is that 'I want this but I do not want that' and 'I want doctors to do what I want'.

D: I do not agree.

T: Well, what would be the diagnosis of these persons?

D: They do not have a diagnosis. Well, at least according to the manual (DSM5).

T: Do you think these people should be considered transsexuals (the word was frequently used by the interview respondent)?

D: No, I do not. I think these are different people. We do not have a diagnosis for them. Probably it will not even be necessary to have a diagnosis for them. Well, we need to understand this and only research can determine what these people mean.

(Practitioner, 70 years old, 40 years of practice, 40 years working with trans people)

Diogo employed a gatekeeping role by limiting access to GD to trans identities outside the normative gender binary while pointing out that more research is needed to understand which diagnosis should be attributed to people who do not conform to the authentic trans ideal. The WPATH in SOC-7 is nevertheless against gatekeeping practices, as it states that gender-confirming medical procedures should be primarily based on patients' decisions and the practitioners' role should be to help patients make informed decisions regarding their transitioning (Davy 2015). The medical validation (Westbrook and Schilt 2014) of trans people who do not intend to change their bodies to conform to the gender binary ideal did not seem to be problematic on the part of practitioners who appeared to follow a social model of gender (Whitehead et al. 2012). This was the case of Mário, who highlighted the fact that some trans people might not wish to undergo genital surgery as they believe this would compromise their gender identity: 
M: I think the majority wants (i.e. to do genital surgery). The majority wants. Well, I would not say that it is an absolute majority. It's a relative majority. People that have not yet decided what they want to do... People that do not want to do gender confirming surgery. Well, with time I believe there will be more people that do not wish to do it.

T: Why do you think with time there will be more?

M: Well, it has to do with what they think is enough for their gender identity. I used to say jokingly... my deconstruction... my prediction... is that in the near future there will be men with vaginas and women with penises.

(Practitioner, 40 years old, 15 years of practice, 15 years working with trans people)

The statement above shows that contrary to what was claimed by Davis et al. (2016), practitioners who work with trans people might challenge the gender binary rhetoric and respect people's decisions regarding their bodies. Like Mário, another practitioner, when asked about the importance of trans people's wish to undergo genital surgery for obtaining the diagnosis of GD, stated:

G: No, no! No, no! That (i.e. genital surgery) does not matter to me.

T: Okay.

G: It's Miguel.

$\mathrm{T}$ : Is it related with the identity?

G: It's Miguel every day. Twenty four hours per day. If he has tits, if he has a penis, if he has a vagina or vulva, it does not matter to me.

(Practitioner, 55 years old, 30 years of practice, 20 years working with trans people)

This group of practitioners did not base their assumptions around the category attribution of GD on "strict cultural meanings around gendered embodiments and experiences" (Dewey and Gesbeck 2017, p. 60). These practitioners did not actively act as gatekeepers but instead tended to facilitate the attribution of the diagnosis of GD by giving trans people the power to define their bodies according to their gender identities. This finding is similar to what Shuster (2016) described as practitioners prioritizing one's self knowledge and appears to be in accord with the guidelines of SOC-7 which enhances a change towards a collaborative model of care where gender-confirming medical procedures should be based first and foremost on trans people's decisions (Davy 2015).

\section{Struggling and accepting gender non-conformity}

The accounts suggest that practitioners who recognize the existence of non-binary gender identities might not feel able to put them in practice. The difficulties regarding the diagnostic attribution of GD to those who do not correspond to the essentialist wrong body ideal (Johnson 2015) were outlined by Francisco:

There is gender diversity... some fit in the diagnosis others don't. The diagnosis serves to guide us in the evaluations that we will propose. The diagno- 
ses also have their history. The diagnosis of Gender Dysphoria is essentially the diagnosis of transsexuality of Harry Benjamin in the 1960s. This relates to notions... the idea that there are people who are living in the wrong body and the idea that people benefit from doing surgery. Well, the diagnosis of Gender Dysphoria aims to understand if a person has this type of dysphoria. That is, a permanent feeling of living in the other gender. Well, the shape of one's body disturbs the development of one's gender identity and expression and people will benefit from hormone and surgical intervention. The diagnosis is this. Well, there are other ways... there is gender diversity. However, the diagnosis cannot be applied. This does not mean in my opinion that there is no medical intervention to offer to these people. What it means is that it might not be the intervention that we offer to transsexuals. I am not thinking in terms of the true and fake transsexual. I am thinking about the existent clinical model for what it means to be a transsexual.

(Practitioner, 30 years old, 5 years of practice, 5 years working with trans people)

This statement is in accord with Davy's (2015) research on the politics of diagnosing trans people, where it was found that the diagnostic framework in the DSM-5 draws upon a binary conception of gender and judges trans people according to their wish to align their genitals with their gender identity through gender-confirming surgery. The view that trans people are interpreted against this backdrop as having a similar trans experience outlined by Shuster (2016) is made apparent in the above statement. What also became evident in the comments of a few practitioners is that there is insufficient updated scientific information available on trans identities and embodiments who do not fit in the authentic trans ideal and that this has a considerable impact on their practice with people who do not position themselves within the gender binary. Thus, without enough scientific evidence practitioners might have difficulty in attributing GD diagnosis and legitimating access to trans-specific healthcare of people with a non-binary gender identity. As Mário explained:

M: Non-binary people are less common in practice. I don't think this is because they think they will be categorized. We have some non-binary people. Well, if we want it or not they represent a bigger challenge.

$\mathrm{T}$ : In what sense do you think they represent a bigger challenge?

M: Because we have to equate what people bring to us to what is written and said in the literature. Even in the literature, each time something new appears there is a delay of at least five years in relation to the new information being available. For example, with the DSM-5: the use of Gender Dysphoria and the abandonment of Gender Identity Disorder. It says: people who do not identify themselves with their assigned gender at birth. Previously what was a reference was the sex. In fact, there are persons who do not identify themselves with their gender and assigned gender at birth but do not totally identify themselves with the opposite gender and want to be more androgynous. This, in terms of our classical evaluation and formal practice, raises some doubts. This raising of doubts does not mean that we doubt what people say but has to do with the diagnosis itself. Well, because 
we know that certain diagnoses give evidence that certain treatments work. That is, a certain population with more gender variability, diversity or fluidity do not correspond with the binary transsexual. I am not sure, and there are no studies which show this, that the same strategies in terms of therapy or surgeries will be equally good for some as it is for others.

(Practitioner, 40 years old, 15 years of practice, 15 years working with trans people)

Mário pointed out that the recent change in the DSM of the use of the term Gender Identity Disorder (GID in DSM-IV) to Gender Dysphoria (GD in DSM-5) allowed room for people with a non-binary gender identity to look for clinical support unlike what happened in the past:

Well, the change from Gender Identity Disorder to Gender Dysphoria... These are different concepts. We are not talking about the same thing. Then, Gender Dysphoria can open a path... as I previously said...for non-binary people to look for help because the focus has more to do with the discomfort that might exist. Well, in terms of the multidisciplinary team and the part medicine plays, we can offer something to these people that might help to diminish the dysphoria.

(Practitioner, 40 years old, 15 years of practice, 15 years working with trans people)

The change from GID to GD aimed to tackle the distress that trans people feel between their assigned gender at birth and their gender identity (Davy 2015; Dewey and Gesbeck 2017). The use of the word trans by practitioners also helps to illustrate their openness to the existence of different gender identities and expressions as the term is more inclusive. This point was outlined by Francisco:

I think the categorization of the word trans has some advantages. I think the advantages of using the word trans is that it calls for a notion of gender diversity. That is, the affirmation that there are other ways of living gender, which are very diverse.

(Practitioner, 30 years old, 5 years of practice, 5 years working with trans people)

We nevertheless found, once again, contrasting viewpoints from practitioners regarding non-binary identities. Trans people who did not desire gender-confirming surgery and thereby did not correspond to the authentic trans ideal were understood by the practitioners who interpreted gender identity within a biological model as not trans enough (Mog and Swarr 2008). The following statement by André clearly shows this point:

The transsexual suffers horrors! The transsexual does everything to equate his/her body with his/her soul. Then he/she will do everything even, as I previously told you, to be submitted to breast surgery without anaesthesia because the anaesthetist was on strike. 
(Practitioner, 45 years old, 20 years of practice, 20 years working with trans people)

The biological gender-identity ideology evident in André's statement is supported by the DSM-5 narrow understanding of trans identities and bodies (Davy 2015). André, who closely followed these guidelines (Shuster 2016), classified trans people who do not wish to change their genitalia and do not intend to move from one binary gender position to the other as abnormal:

T: What do you think about people who define themselves as non-binary?

A: I think it is bizarre! I think it is a nonsense!

T: Why?

A: Why? Because there is no such thing! People are what they are! People... human beings... human beings are what they are. That is, a complex being. Humans are masculine or feminine. It is a genetic thing. Do you understand?

This view on trans embodiments is in line with Davis et al. (2016) research on intersex (people who are born with both male and female biological characteristics including genital, gonadal and/or chromosomal) and medicalization practices, where it was found that any embodiment which does not align biological sex, gender identity and sexuality according to the heterosexual imaginary is understood by practitioners as pathological and morbid. As outlined earlier, we found contrasting positions on this matter and a more nuanced perspective on the part of practitioners who work with trans people than that described in previous studies (Johnson 2015; Davis et al. 2016; McQueen 2016; Dewey and Gesbeck 2017).

\section{Discussion}

The current study aimed to provide a better understanding of gender subjectivities within the diagnostic attribution of GD by practitioners who work with trans people in Portugal. The findings highlighted here offer a more nuanced perspective on transspecific healthcare practices than that described in research conducted in Portugal (Pinto and Moleiro 2012) and elsewhere (Davis et al. 2016). Practitioners' accounts on the attribution of the diagnosis of GD show a diversity not sufficiently acknowledged within sociological and transgender literature-although there have been a few exceptions (Whitehead et al. 2012; Shuster 2016). We further extend these studies (ibid) by demonstrating that practitioners who operate under a social model of gender are opening space for trans people to be treated as experts of their bodies and identities. While it might not be true for practitioners who can be positioned within a biological model of gender, we found evidence that practitioners who work with trans people are allowing room for the self-definition of gender identification.

Within a country characterized by a strong welfare state like Portugal, it was not surprising a paternalistic approach to the diagnostic attribution of GD (Linander et al. 2017a), where practitioners act as gatekeepers (Hilário 2018), underpinned by the belief they are acting in the best interests of patients (Silva and Osswald 2010), i.e. in this case the best interests of trans persons, was adopted. Nevertheless, by 
employing a gatekeeping role and following a biological model of gender practitioners are in fact limiting the access to GD diagnosis and therefore to gender-confirming medical procedures of trans people who do not conform to the gender binary ideal and compromising their rights to trans-specific healthcare (Davis et al. 2016). This might be the case for trans people who position themselves within the genderqueer umbrella and might wish, for instance, to take hormones for breast augmentation without ever doing genital surgery, to undertake top surgery to remove their breasts without ever taking hormones or undergoing genital surgery, to undergo genital surgery without doing breast augmentation or pursue hormone transition.

Unlike the practitioners who follow a biological model, the practitioners who can be positioned within what Whitehead et al. (2012) refer to as a social model of gender did not limit the attribution of GD diagnosis and access to trans-specific healthcare to trans people who identify beyond gender binary. Practitioners who were open to the existence of a variety of gender identities and expressions made some efforts to integrate, as best they could, gender diversity in their practice despite the lack of guidelines in DSM-5 regarding this matter. These practitioners appeared to support the collaborative approach to care enhanced by the WPATH by giving trans people the chance to make their own decisions regarding their gender identification and, ultimately, their transitioning. The WPATH believes that a collaborative model would help to reduce the worldwide problems concerning access, provision and delivery of trans-specific healthcare, in particular for trans people who do not conform to the gender binary ideal (Davy 2015).

The findings presented here support Linander et al. (2017b) argument that practitioners who work with trans people should have a more confirming approach to care which potentiates the self-determination of trans people instead of the conforming approach evident here in the practices employed by the practitioners who follow a biological model of gender. The practitioners who employed a social model of gender in their work are in line with the wishes and needs of trans people who do not conform to the gender binary ideal by allowing them room for the self-definition of gender identification and respecting their rights to trans-specific healthcare. In contrast to Linander et al. (2017b) who conducted research with trans people about trans-specific healthcare practices, we offer empirical evidence from those in the hands of care, i.e. on the part of medical and psychological practitioners who work with trans people. Unlike what has been described by Davis (2015) in their research about the medicalization of intersexuality, we found evidence that practitioners who follow a social model of gender have been, to a certain extent, influenced by the theoretical arguments of feminist scholarship. Thus, our findings are in line with the suggestion made by Linander et al. (2017b) that an awareness and critical thinking about gender binary norms could help to change trans-specific healthcare practices.

The study provides another lens for understanding the diagnostic attribution of GD by paying attention to the accounts of practitioners and shedding light on those who embrace the self-definition of gender identification. Thus, our work and that of a few others (Whitehead et al. 2012; Shuster 2016) show heterogeneity amongst the practices employed by the medical and psychological practitioners who work with trans people. We outlined the nuances and complexities around the diagnostic attribution of GD and highlighted how ideologies regarding gender shape this 
attribution in Portugal. The openness on the part of some practitioners towards the self-definition of gender identification cannot be isolated from the political debate over the dissociation between medical and legal gender recognition that has been taking place in Portugal and across the globe (Davy et al. 2018; Hilário 2018). The conclusions presented here are tentative and further research is required with practitioners in other contexts to understand the extent to which they are allowing room for the self-definition of gender identification. We claim that the change towards the self-determination of trans people in Portugal and elsewhere needs to go hand in hand with appropriate changes in clinical guidelines, particularly regarding nonbinary gender identities.

Acknowledgements The reflection developed drew on data collected in the frame of the European Research Council funded project TRANSRIGHTS: Gender citizenship and sexual rights in Europe: Transgender lives in transnational perspective. The project reflects only the views of the author, and the European Union cannot be held responsible for any use which may be made of the information contained therein. I would like to express my gratitude to TRANSRIGHTS Coordinator Sofia Aboim, who encouraged my participation in the project for her expertise and guidance during the construction of this article. I would like to thank the practitioners who agreed to take part in the TRANSRIGHTS project.

Funding The research leading to these results has received funding from the European Research Council under the European Union's Seventh Framework Programme (FP7/2007-2013)/ERC Grant Agreement No. 615594.

Open Access This article is distributed under the terms of the Creative Commons Attribution 4.0 International License (http://creativecommons.org/licenses/by/4.0/), which permits unrestricted use, distribution, and reproduction in any medium, provided you give appropriate credit to the original author(s) and the source, provide a link to the Creative Commons license, and indicate if changes were made.

\section{References}

APA (American Psychiatric Association). 2013. The diagnostic and statistical manual of mental disorders, 5th ed. Arlington, VA: American Psychiatric Association.

Braun, V., and V. Clarke. 2006. Using thematic analysis in psychology. Qualitative Research in Psychology 3 (2): 77-101.

Castagnoli, C. 2010. Transgender persons' rights in EU member states. Brussels: EU.

Connell, C. 2010. Doing, undoing or redoing gender? Learning from the workplace experiences of transpeople. Gender \& Society 24 (1): 31-55.

Connell, R. 2012. Transsexual women and feminist thought: Toward new understanding and new politics. Signs 37 (4): 857-881.

Davis, G. 2015. Contesting intersex: the dubious diagnosis. New York: New York University Press.

Davis, G., J. Dewey, and E. Murphy. 2016. Giving sex: Deconstructing intersex and trans medicalisation practices. Gender \& Society 30 (3): 490-514.

Davy, Z. 2015. The DSM-5 and the politics of diagnosing trans people. Archives of Sexual Behaviour 44: 1165-1176.

Davy, Z., A. Sorlie, and A. Schwend. 2018. Democratising diagnosis? The role of the depathologisation perspective in constructing corporeal trans citizenship. Critical Social Policy 38 (1): 13-34.

Dewey, J.M., and M.M. Gesbeck. 2017. (Dys) functional diagnosing: Mental health diagnosis, medicalisation, and the making of transgender patients. Humanity \& Society 41 (1): 37-72.

Hilário, A.P. (2018) Rethinking trans identities within the medical and psychological community: a path towards the depathologization and self-definition of gender identification in Portugal? Journal of Gender Studies. 
Hilário, A.P. 2017. Contestation, instrumental resistance and strategic conformation within the diagnostic process of Gender Dysphoria in Portugal. Health: An Interdisciplinary Journal for the Social Study of Health, Illness and Medicine 21 (5): 555-572.

Hird, M.J. 2002. For a sociology of transsexualism. Sociology 36: 577-595.

Ingraham, C. 1994. The heterosexual imaginary: Feminist sociology and theories of gender. Sociological Theory 12 (2): 203-219.

Linander, I., E. Alm, A. Hammarstrom, and L. Harryson. 2017a. Negotiating the (bio)medical gazeExperiences of trans-specific healthcare in Sweden. Social Science and Medicine 174: 9-16.

Linander, I., E. Alm, I. Goicolea, and L. Harryson. 2017b. 'It was like I had to fit into a category': Careseekers' experiences of gender regulation in the Swedish trans-specific healthcare. Health: An Interdisciplinary Journal for the Social Study of Health, Illness and Medicine 0: 1-18.

Johnson, A.H. 2015. Normative accountability: How the medical model influences transgender identities and experiences. Sociology Compass 9 (9): 803-813.

McQueen, P. 2016. Authenticity, intersubjectivity and the ethics of changing sex. Journal of Gender Studies 25 (5): 557-570.

Mog, A., and A.L. Swarr. 2008. Threads of commonality in transgender and disability studies. Disability Studies Quarterly 28: 4.

Pfeffer, C. 2010. 'Women's work'? Women partners of transgender men doing housework and emotion work. Journal of Marriage and Family 72: 165-183.

Pinto, N., and C. Moleiro. 2012. As experiências dos cuidados de saúde de pessoas Transexuais em Portugal: perspetivas de profissionais de saúde e utentes. Psicologia, XXV I (1): 129-151.

Pinto, N., and C. Moleiro. 2015. Gender trajectories: Transsexual people coming to terms with their gender identities. Professional Psychology: Research and Practice 46 (1): 12-20.

Platero, R. 2011. The narratives of transgender rights mobilization in Spain. Sexualities 14 (5): 597-614.

Richard, C., M. Barker, P. Lenihan, and A. Iantaffi. 2014. Who watcher the watchmen? A critical perspective on the theorization of trans people and clinicians. Feminism \& Psychology 24 (2): 248-258.

Sanger, T. 2010. Trans people's partnerships: Towards an ethics of intimacy. Hampshire, New York: Palgrave Macmillan.

Santos, A. 2013. Sexual movements and sexual citizenship in Southern Europe. Houndmills, Basingstoke, Hampshire: Palgrave Macmillan.

Silva, E.M., and W. Osswald. 2010. Medical paternalism or parental autonomy in decision making: A Portuguese study in premature newborns. AJOB Primary Research 1 (4): 4-8.

Schilt, K., and L. Westbrook. 2009. Doing gender, doing heteronormativity 'gender normals', transgender people, and the social maintenance of heterosexuality. Gender \& Society 23 (4): 440-464.

Shuster, S. 2016. Uncertain expertise and the limitations of clinical guidelines in transgender healthcare. Journal of Health and Social Behavior 57 (3): 319-332.

Turowetz, J., and D. Maynard. 2016. Category attribution as a device for diagnosis: Fitting children to the autism spectrum. Sociology of Health \& Illness 38 (4): 610-626.

Westbrook, L., and K. Schilt. 2014. Doing gender, determining gender: Transgender people, gender panics and the maintenance of the sex/gender/sexuality system. Gender \& Society 28 (1): 32-47.

Whitehead, J.C., J. Thomas, B. Forkner, and D. LaMonica. 2012. Reluctant gatekeepers: 'Trans-positive' practitioners and the social construction of sex and gender. Journal of Gender Studies 21 (4): 387-400.

WPATH (World Professional Association for Transgender Health). 2011. Standards of care for the health of transsexual, transgender, and gender nonconforming people (7th edn.). Accessed at https://www. wpath.org/media/cms/Documents/Web\%20Transfer/SOC/Standards\%20of\%20Care\%20V7\%20 -\%202011\%20WPATH.pdf.

Publisher's Note Springer Nature remains neutral with regard to jurisdictional claims in published maps and institutional affiliations.

Ana Patrícia Hilário is a post-doctoral fellow under the framework of the TRANSRIGHTS project, funded by the European Research Council, at the Instituto de Ciências Sociais, Universidade de Lisboa (ICSULisboa). She holds a PhD in Sociology (Royal Holloway, University of London) and a BSc in Sociology (ISCTE-Instituto Universitário de Lisboa). She has previously worked as a research assistant at the 
ISCTE-Instituto Universitário de Lisboa, Instituto Superior de Ciências Sociais e Políticas and Instituto de Ciências Sociais, Universidade de Lisboa. Her current main research interests focus on the Sociology of Health and Illness, Sociology of Diagnosis, Sociology of Gender and Sociology of Childhood and Youth. 